\title{
Retraction Note: High doses of garlic extract significantly attenuated the ratio of serum LDL to HDL level in rat-fed with hypercholesterolemia diet
}

Tahereh Ebrahimi ${ }^{1}$, Behnoosh Behdad ${ }^{2}$, Maryam Agha Abbasi ${ }^{3,4}$, Rahman Ghaffarzadegan Rabati ${ }^{5}$, Amir Farshid Fayyaz ${ }^{6}$, Vahid Behnod ${ }^{7}$ and Ali Asgari ${ }^{8^{*}}$

\section{Retraction}

The Editor-in-Chief and Publisher have retracted this article [1] because the scientific integrity of the content cannot be guaranteed. An investigation by the Publisher found it to be one of a group of articles we have identified as showing evidence suggestive of attempts to subvert the peer review and publication system to inappropriately obtain or allocate authorship. This article showed evidence of plagiarism (most notably from the articles cited [2-4]) and authorship manipulation.

\footnotetext{
Author details

'Department of Agricultural Biotechnology, Sari Agricultural Sciences and Natural Resources University, Sari, Iran. ${ }^{2}$ Shahid Beheshti University of Medical Sciences, Tehran, Iran. ${ }^{3}$ Department of Biochemistry, College of Science, Kurdistan Science and Research Branch, Islamic Azad University, Sanandaj, Iran. ${ }^{4}$ Danesh Pathobiology Laboratory, Tehran, Iran. ${ }^{5}$ Shahid Abbas Abdollahi, Molecular Biology Research Center of Shahid Mahallati Hospital, Tabriz, Iran. ${ }^{6}$ Department of Legal Medicine, AJA University of Medical Sciences, Tehran, Iran. 'Baqiyatallah University of Medical Sciences, Tehran, Iran. ${ }^{8}$ Department of Infectious Diseases, AJA University of Medical Sciences, Tehran, Iran.
}

Received: 17 October 2016 Accepted: 19 October 2016

Published online: 02 November 2016

\section{References}

1. Ebrahimi T, Behdad B, Abbasi MA, Rabati RG, Fayyaz AF, Behnod V, Asgari A. High doses of garlic extract significantly attenuated the ratio of serum LDL to HDL level in rat-fed with hypercholesterolemia diet. Diagn Pathol. 2015;10:74.

2. Thomson M, Al-Qattan KK, Bordia T, Ali M. Including garlic in the diet may help lower blood glucose, cholesterol, and triglycerides. J Nutr. 2006;136(3 Suppl): 800S-2S.

3. Heidarian E, Jafari-Dehkordi E, Seidkhani-Nahal A. Effect of garlic on liver phosphatidate phosphohydrolase and plasma lipid levels in hyperlipidemic rats. Food Chem Toxicol. 2011;49(5):1110-4.

4. Sohn CW, Kim H, You BR, Kim MJ, Kim HJ, Lee JY, Sok D-E, Kim JH, Lee KJ, Kim MR. High temperature- and high pressure-processed garlic improves lipid profiles in rats fed high cholesterol diets. J Med Food. 2012;15(5):435-40.

* Correspondence: aliasgari296@yahoo.com

${ }^{8}$ Department of Infectious Diseases, AJA University of Medical Sciences, Tehran, Iran 